\title{
A produção independente e a desverticalização da cadeia produtiva da música
}

\section{Independent producers and outsourcing in the music value chain}

\author{
Davi Nakano'
}

\begin{abstract}
Resumo: Desde o anos 1950, a indústria fonográfica vem passando por transformações sucessivas, comandadas pelo desenvolvimento tecnológico. De um setor dominado por grandes empresas verticalizadas, com pequena diversidade de produtos, ela passou a ser uma indústria na qual pequenas e médias empresas desempenham papel importante na prospecção de tendências e lançamento de produtos. Nela, as atividades de manufatura e distribuição são executadas por fornecedores especializados, e o mercado é compartilhado entre as grandes e as pequenas e médias empresas. A Cadeia de Produção Musical vem passando atualmente por uma fase de incertezas e indefinições, devido às novas possibilidades criadas pela chamada "desmaterialização da música", isto é, a distribuição de música pela internet ou pela telefonia celular. Este texto apresenta a evolução da cadeia de produção musical e destaca dois exemplos de empresas brasileiras que desenvolvem novas atividades e competências que exploram as possibilidades existentes na atual configuração da cadeia brasileira.
\end{abstract}

Palavras-chave: Desverticalização. Indústrias criativas. Cadeia de produção musical. Inovação tecnológica.

\begin{abstract}
Abstract: The phonographic industry has undergone successive changes since the 1950s driven by technological innovation. It used to be dominated by a few large integrated firms, and a limited variety of products, but small and medium-sized enterprises (SMEs) have grown in importance and are considered the drivers of change and innovation. In that new scenario, specialized service providers perform manufacturing and logistics activities, and the market is shared between large and SMEs. The Internet and mobile communications have opened new possibilities for content distribution, and the phonographic industry has been facing uncertainties since the early 2000. This study describes the evolution of the phonographic industry and analyzes two independent Brazilian firms, which developed competencies to explore new business possibilities in the current business scenario.
\end{abstract}

Keywords: Outsourcing. Creative indutries. Music value chain. Technology. Innovation.

\section{Introdução}

Cultura e arte, além de manifestações de talento e criatividade, são hoje importantes atividades econômicas, que produzem qualificações, criam e exploram novos espaços sociais, promovem reurbanização e induzem o desenvolvimento de outras atividades. $\mathrm{O}$ conjunto das atividades culturais recebe diversas denominações: considerando-se, por exemplo, a origem da atividade artística e cultural, o talento humano, fala-se na indústria da criatividade (CAVES, 2000). Se por outro lado se considera a finalidade da atividade, o lazer e a diversão, fala-se em indústria do entretenimento (VOGEL, 2004; VINET, 2005). A UNESCO define Indústrias da Cultura (Cultural Industries) como os setores que realizam atividades de criação, produção e comercialização de conteúdo intangível e de natureza cultural (UNESCO, 2006).

A produção musical é considerada por alguns como o mais fundamental entre os negócios das indústrias da criatividade (VOGEL, 2004), por participar direta ou indiretamente do resultado de diversos outros negócios. No mercado fonográfico mundial, a produção e a comercialização de música gravada em suportes físicos (CDs, DVDs, VHS, singles e cassetes) e de música digital movimentaram US $\$ 33,5$ bilhões em 2005 (INTERNATIONAL FEDERATION OF THE PHONOGRAPHIC INDUSTRY, 2006), sem contar receitas de apresentações ao vivo e de direitos autorais. No âmbito do mercado nacional, os associados da Associação Brasileira de Produtores de Discos (ABPD) movimentaram $\mathrm{R} \$$ 615,2 milhões em vendas de suportes físicos durante o mesmo ano (ASSOCIAÇÃO BRASILEIRA DOS PRODUTORES DE DISCOS, 2006).

A organização do mercado musical é recente. Por exemplo, o mercado norte-americano, o maior do mundo em 2006 (INTERNATIONAL FEDERATION OF THE PHONOGRAPHIC INDUSTRY, 2007), começou a se organizar no final do século XIX, atingindo escala

\footnotetext{
${ }^{1}$ Departamento de Engenharia de Produção, Escola Politécnica, Universidade de São Paulo - USP, E-mail: dnnakano@usp.br Recebido em 3/9/2008 — Aceito em 21/7/2010
}

Suporte financeiro: FAPESP. 
nacional com a melhoria dos transportes e meios de comunicação. Nessa fase pioneira, as receitas eram provenientes de apresentações ao vivo e, somente na década de 1940, a venda de música gravada (aquela registrada em suportes físicos), embora fosse disponível desde o início daquele século, passou a ser a maior fonte de receita das empresas do setor (ANAND; PETERSON, 2000).

O mercado de música gravada é estruturado, desde a sua criação, por um oligopólio. A quantidade e a identidade das grandes empresas variaram ao longo dos anos e, na atualidade, as majors, como são conhecidas as grandes empresas, são quatro. Entretanto é evidente que a atividade de produção e comercialização de fonogramas não se limita às grandes corporações: além de artistas-empreendedores (profissionais que sem o auxílio de gravadoras conseguem, mesmo que de forma limitada, ser bem-sucedidos no mercado), as majors, desde a década de 1950, têm convivido com pequenas e médias gravadoras independentes, também conhecidas por indies. Dessa forma, a estrutura do mercado de produção musical é dividida entre grandes empresas, que com grande poder econômico dominam a maior parte dos negócios, e pequenas e médias empresas, que embora frágeis, são consideradas por muitos como aquelas que inovam e procuram equilibrar interesses comerciais com qualidade artística.

O produto das gravadoras é composto de uma parte intangível, o conteúdo musical, e um suporte, o qual enquanto físico, passou sucessivamente de um cilindro de cera, para discos em laca e depois em vinil (durante as décadas de 1970 e 80 os vinis conviveram com as fitas magnéticas), até o surgimento da tecnologia digital e dos discos em policarbonato, a partir de meados da década de 1980. Embora o produto fonográfico seja muitas vezes visto como uma unidade indivisível, ele tem, na realidade, dois processos produtivos bastante distintos: a produção do conteúdo e a do suporte. Morelli (2009) comenta que a distinção é tão acentuada que pode ser dita como acontecendo em dois "mundos": o do estúdio (produção de conteúdo) e o da fábrica (produção do suporte), caracterizados por relações de trabalho e lógicas de produção próprias. A produção de conteúdo tem sido estudada a partir de duas perspectivas: uma mais vinculada à Sociologia, que estuda a produção de conteúdo como forma de expressão cultural (e.g. PETERSON, 1990; ALEXANDER, 1994), e outra, mais eclética, que discute a estratégia das empresas e seus modelos de negócio (PAPAGIANNIDIS; BERRY; PETCHEY, 2005), a organização do trabalho das empresas de produção de conteúdo (TOWNLEY; BEECH; McKINLAY, 2009), e o impacto tecnológico no setor e em suas operações (ALKMIN et al., 2005; LEYSHON et al., GRAHAM et al., 2004). A primeira vertente, enraizada na sociologia da cultura, mesmo reconhecendo a produção do suporte como parte da atividade, focaliza a produção de conteúdo, enquanto a segunda entende a indústria como um processo único, integrado, no qual produção de conteúdo e do suporte faz parte de um fluxo contínuo.

Embora o processo possa ser visto como único, o advento da internet trouxe uma grande modificação no mercado de música: o desenvolvimento da técnica de compactação de arquivos (como o formato MP3) e do acesso de alta capacidade (banda larga) possibilitam agora a distribuição de música sem o suporte físico. O resultado disso é que a ligação entre o conteúdo e o suporte se tornou ainda mais fraca: se antes os processos produtivos aconteciam em locais diferentes, porém a distribuição do conteúdo dependia da produção do suporte físico, agora essa vinculação foi desfeita. Adicionalmente, a distribuição virtual prescinde de canais de distribuição específicos, como lojas especializadas, podendo ser feita pela internet ou utilizando a telefonia móvel. A distribuição virtual vem crescendo de forma expressiva desde o início dos anos 2000. Mesmo considerando o mercado formal de música, certamente pequeno quando se fala em distribuição virtual, o crescimento é expressivo: a venda de música digital cresceu de praticamente zero em 2003 para cerca de $17 \%$ das vendas totais em 2007, segundo informações do sítio da ABPD.

Um produto modular é aquele composto por subconjuntos com funções específicas e com interfaces padronizadas, que permitem a modificação de um subconjunto sem alterações nos demais (ULRICH, 1995). As implicações do projeto modular ultrapassam o produto e atingem as próprias empresas produtoras: produtos modulares permitem a modularização da estrutura das empresas (BRUSONI; PRENCIPE, 2001) e da própria cadeia produtiva (GEREFFI; HUMPHREY; STURGEON, 2005). O caráter modular do produto fonográfico, por restrições técnicas, ficou oculto por décadas. A digitalização do conteúdo e sua distribuição virtual quebraram a relação conteúdo - suporte físico, e evidenciaram o seu caráter modular. Uma das consequências é a convergência entre a indústria fonográfica e a indústria de telecomunicações, na qual uma produz o conteúdo enquanto a outra o distribui. Assim, a modularização do produto fonográfico tem impacto na estrutura do setor, nos modelos de negócio e nos canais de distribuição utilizados. Porém, apesar de mais evidente na atualidade, a modificação da cadeia produtiva da música é processo que teve início há 50 anos. Naquela época, a indústria fonográfica era dominada por grandes empresas verticalizadas, que, progressivamente, passaram a dividir o mercado com empresas de pequeno e médio porte, ao mesmo tempo em que, mais recentemente, externalizaram suas atividades de manufatura e distribuição. Este texto levanta os fatores apontados pela literatura para o processo de desverticalização, e analisa progressiva transformação da cadeia produtiva da 
indústria fonográfica por meio deles. Cabe esclarecer que os termos cadeia produtiva da música ou da produção musical são utilizados neste texto como referência somente à produção de música gravada, aquela registrada em suportes físicos ou arquivos digitais, porém deve-se notar que, de forma mais ampla, a produção musical engloba também a oferta de serviços como apresentações ao vivo, o que não é contemplado neste texto.

\section{Desverticalização e externalização de atividades produtivas}

A corporação verticalizada foi uma forma organizacional comum entre as grandes empresas até o final do século XX. A partir das últimas décadas daquele século, grandes empresas começaram a abandonar a forma verticalizada, externalizando não somente atividades de apoio, como também manufatura e distribuição e investindo em desenvolvimento colaborativo de produtos. A literatura aponta um conjunto de fatores para explicar por que a grande corporação transformou-se, reduziu suas dimensões e o escopo de suas atividades. Em primeiro lugar o desenvolvimento técnico levou algumas rotas tecnológicas à redução da escala econômica de produção, eliminando os ganhos de escala das plantas com elevada capacidade. Estas exigiam coordenação e alta velocidade de atravessamento do sistema produtivo (STURGEON, 2002; TIGRE, 2006) para atingir eficiência produtiva, que eram mais facilmente conseguidos pelas operações internas.

As escalas produtivas menores resultaram na redução dos investimentos necessários para a produção, diminuindo as barreiras de entrada financeiras (LANGLOIS, 2003), e diminuiu a vantagem de velocidade das grandes plantas. Com isso, o mercado se abriu para pequenos fornecedores, mais flexíveis e dinâmicos que as grandes corporações, que começaram a explorar nichos de mercado que aquelas não identificaram ou não tiveram interesse em atender. Progressivamente, estes fornecedores aumentaram seu volume produtivo e passaram a oferecer seus serviços para as grandes corporações.

O desenvolvimento das empresas ao longo do tempo também criou competências a seu redor. $\mathrm{O}$ conhecimento técnico e gerencial desenvolvido por ela se disseminou, voluntária ou involuntariamente, para fornecedores e clientes. Uma parte dos profissionais treinados dentro delas se moveu no mercado de trabalho, ajudando a disseminar competências para outras empresas, enquanto outros, empreendedores, criaram as suas próprias (MALERBA et al., 2008). A disseminação do conhecimento no setor e a criação de competências distribuídas possibilitou a formação de fluxos de produtos e serviços entre elas.

$\mathrm{O}$ amadurecimento das relações de fornecimento entre empresas levou à criação de especificações e padrões para tornar os fluxos eficientes. A evolução dos padrões, que passaram de particulares entre empresas para gerais da indústria, criou especificações definindo desempenho e interfaces entre componentes, o que possibilitou o estabelecimento de fornecedores especializados universais, capazes de produzir componentes e subconjuntos para diversas empresas (STURGEON, 2002). Em outros casos, o produto evolui para um projeto modular, o que tornou a padronização de interfaces não apenas necessária, mas mandatória (LANGLOIS, 2003). Existe na verdade uma relação estreita entre padronização e modularização no projeto: quando a primeira atinge níveis elevados de confiabilidade e disseminação, ela incentiva a segunda. $\mathrm{O}$ efeito da padronização e da modularização é a redução da especificidade dos ativos produtivos, pois possibilita o estabelecimento de fornecedores que atendem a diferentes clientes, produzindo famílias de componentes e subsistemas. A disseminação de competências e da modularização e padronização é outro fator que explica o surgimento dos grandes fornecedores especializados, com competência técnica e elevada capacidade produtiva, cuja oferta de serviços desestimulou as grandes empresas a manterem capacidade interna (STURGEON, 2002).

A reestruturação das grandes corporações também pode ser relacionada ao próprio crescimento do mercado. Quando o mercado atinge um tamanho tal que mesmo dividido entre competidores ainda tem volume suficiente para garantir receitas elevadas para cada um deles, reduz-se o impacto dos custos fixos, e por consequência, o risco da operação. Ao mesmo tempo, o crescimento do mercado atrai novas empresas, entre elas os fornecedores especializados, que possibilitam a externalização de atividades (LANGLOIS, 2003; MALERBA et al., 2008).

O desenvolvimento tecnológico, a evolução técnica das empresas do setor, o crescimento dos mercados e de suas instituições são fatores que explicam os movimentos de desverticalização das empresas. Quando investimentos e riscos eram altos e a disseminação de competências no setor era baixa, as empresas se verticalizaram. Quando, por outro lado, o desenvolvimento tecnológico reduziu investimentos, o crescimento do mercado diminuiu riscos, e as competências técnicas se disseminam no setor, criaram-se condições para a externalização das atividades. É evidente que os fatores são correlacionados e o seu efeito isolado é, na prática, difícil de ser determinado. Portanto, a análise de uma indústria deve analisar esses fatores conjuntamente, e como eles não evoluem simultaneamente nem de uma forma equilibrada, a cada nova configuração, um novo arranjo pode se estabelecer (LANGLOIS, 2003). A Figura 1 resume os fatores apresentados, que serão utilizados na análise da indústria fonográfica. 


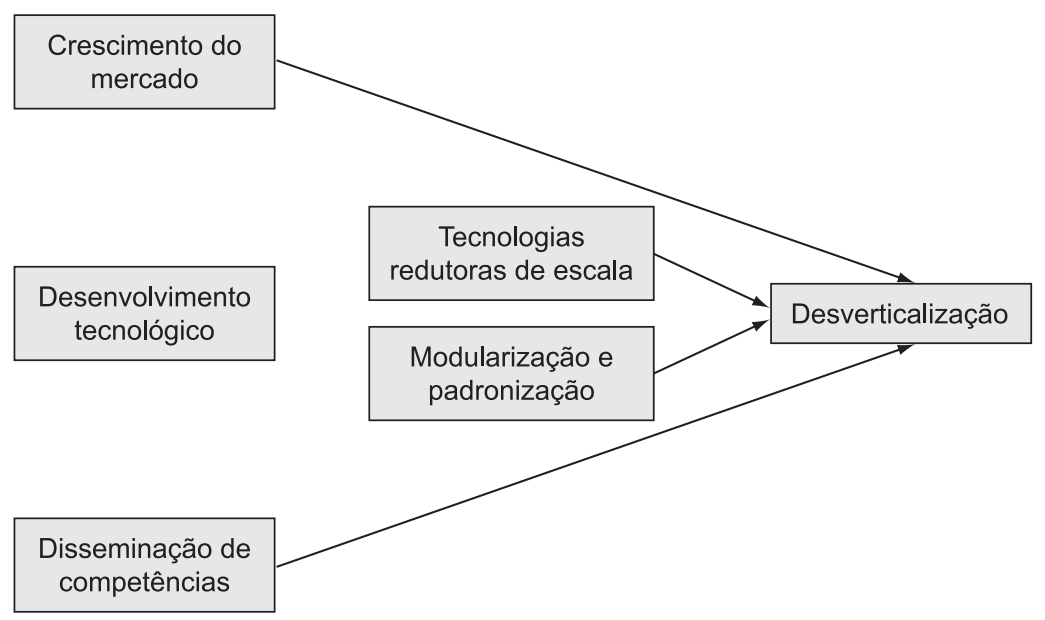

Figura 1. Fatores para a desverticalização produtiva. Fonte: o autor.

\section{A produção de música gravada}

A indústria de produção musical se organizou a partir da inovação tecnológica, passando de um setor tipicamente de serviços para um com características de manufatura, graças ao desenvolvimento das técnicas de gravação de som. Até o final do século XIX, o consumo de música era possível somente em apresentações ao vivo, já que não havia tecnologia de gravação de som comercialmente viável. Naquela época, na América do Norte, a produção e o consumo de música se organizavam ao redor das editoras e publicadoras de partituras musicais, dos grupos musicais que faziam apresentações ao vivo e das casas de espetáculos. O consumo era muito limitado e só apresentou algum crescimento com a evolução dos meios de transportes, que permitiram a maior disseminação das partituras por aquele país (ANAND; PETERSON, 2000).

O desenvolvimento tecnológico possibilitou o surgimento da indústria de produção musical, como a invenção do fonógrafo. Durante as primeiras décadas do século $\mathrm{XX}$, diversas empresas começaram a produzir e comercializar equipamentos de reprodução, popularizando marcas como Gramophone e Victrola, que se tornaram praticamente sinônimos de aparelhos de reprodução de sons gravados em suportes circulares (os "discos"). A produção de música gravada era realizada pelas próprias empresas que produziam e comercializavam os equipamentos de reprodução (todos protegidos por patentes) como forma de alavancar suas vendas. Muitos dos primeiros registros musicais comercializados tinham como objetivo principal permitir o uso do aparelho reprodutor e não a divulgação da obra artística em si.

A indústria entrou em uma fase de dormência entre as décadas de 1930 e 1940 (ALEXANDER, 1994). A recessão mundial e a deflagração da II Grande Guerra somada a fatores microeconômicos como os altos custos de produção desaceleraram a indústria nascente. Na gravação, sem a existência de processos de reprodução em larga escala, músicos precisavam executar repetidas vezes as peças musicais a serem gravadas (McCOURT; BURKART, 2003), elevando os custos de produção, enquanto na produção de suportes, a matéria-prima de origem animal (a laca, ou shellac) era escassa e cara, além de tecnicamente limitada.

A partir da década de 1940, o setor foi dominado por um oligopólio, cujos participantes passaram a ser conhecidos como majors. Sua vantagem temporária inicial das patentes foi estendida por meio do controle sobre recursos-chave na produção, pela propriedade dos estúdios de gravação, e na distribuição, por meio da influência sobre os pontos de venda, e pelo acesso privilegiado aos meios de promoção e divulgação, o que conferiu poder a essas empresas (PETERSON; BERGER, 1975). Outro fator que permitiu seu domínio foi o fato de grande parte dos custos da exploração da atividade musical serem irrecuperáveis, pois não é possível garantir a priori o sucesso de um artista, o que resultou em uma barreira de entrada financeira. (PETERSON; BERGER, 1975).

A década de 1950 marcou a decolagem da indústria de produção musical (PETERSON; BERGER, 1975; ALEXANDER, 1994; STROLB; TUCKER, 2000). Além da melhoria do panorama macroeconômico com o final da II Guerra, foi decisiva para o crescimento da indústria a redução nos custos de produção, resultante do desenvolvimento de tecnologias complementares de gravação e produção. A utilização de novas matérias-primas sintéticas para os suportes físicos, mais abundantes, baratas e resistentes, permitiram menores custos, maior distribuição e melhor qualidade sonora. Desenvolveu-se também a gravação em fitas magnéticas, que, ao permitir regravação, edição e montagem (i.e. o recorte de trechos mal executados e sua substituição sem a necessidade de reexecução 
da peça inteira), reduziu drasticamente os custos de produção (ALEXANDER, 1994). Consolidou-se ainda um padrão de suporte físico, o disco de 12 pol. de diâmetro e microrranhuras, chamado de long playing record (LP) (STROLB; TUCKER, 2000), o que permitiu a padronização dos aparelhos reprodutores.

A queda nos custos de produção foi acompanhada pelo crescimento do mercado, o que tornou possível o surgimento de pequenas gravadoras independentes. Essas empresas valeram-se da facilidade de entrada no mercado e começaram a explorar novos gêneros musicais, deixados de lado pelas majors, especialmente os de influência afro-americana, como o rhythm and blues e o rock. As gravadoras independentes estabeleceram-se e se consolidaram no mercado com sua imagem ligada a nichos de mercado e à exploração de gêneros inovadores.

A partir da década de 1950, a maior parcela das receitas da indústria passou a provir da música gravada, por meio da venda de discos e dos direitos cobrados pela execução nas rádios, nas máquinas automáticas (jukeboxes) e no cinema, superando a receita das vendas de partituras e das apresentações ao vivo (ANAND; PETERSON, 2000). Com a produção de suportes físicos duráveis, baixos custos de produção, a expansão do número de reprodutores e o contínuo crescimento da demanda, a indústria se fortaleceu e experimentou três décadas de crescimento contínuo, interrompida somente no início da década de 1980.

A retração das vendas na década de 1980 foi superada pela indústria fonográfica, não só devido ao final da recessão mundial, mas também pela introdução da tecnologia digital e do novo padrão de suporte físico a ela associada, o Compact Disk (CD), mais resistente, durável e, em determinados aspectos, de melhor qualidade. Quando os reprodutores de CDs se popularizaram, incorporados a aparelhos domésticos, aos automotivos, e aos portáteis individuais (HANSMAN et al., 1999), a indústria experimentou nova fase de crescimento das vendas, interrompida somente no início dos anos 2000.

A tecnologia digital não modificou somente o suporte físico e os reprodutores de música. Ela derrubou investimentos e os custos de gravação de matrizes, ao possibilitar o uso de computadores pessoais para estas tarefas. Até aquele momento, a gravação de matrizes em fita magnética significava investimentos em equipamentos especializados e sofisticados, cujo acesso, embora possível, era restrito a poucos. O uso dos computadores pessoais determinou expressiva queda nos investimentos, que passaram a ser acessíveis não só a empresas, como também para indivíduos, permitindo, por exemplo, que os próprios artistas e produtores montassem pequenos estúdios de gravação, os chamados bedroom studios (ALEXANDER, 1994; HESMONDHALGH, 1998), e passassem a gravar com qualidade aceitável para o mercado. A tecnologia digital foi, para a indústria fonográfica, redutora de escala, criando possibilidades técnicas de baixo custo, baixo volume e alta qualidade (ALEXANDER, 1994). A consequência foi uma nova onda de surgimento de estúdios e gravadoras independentes.

Se entre as décadas de 1980 e 1990 as tecnologias digitais tiveram impacto principalmente sobre os processos de produção, seja de matrizes como dos suportes, o uso da internet vem modificando as atividades de distribuição na cadeia produtiva da música. Embora a conversão do sinal sonoro analógico para digital fosse utilizada comercialmente nos CDs desde a década de 1980, a sua transmissão pela internet permaneceu impraticável por algum tempo pelo tamanho dos arquivos sonoros e as velocidades de transmissão disponíveis. O desenvolvimento de técnicas de compactação de arquivos sonoros digitais (formatos como o MP3, OGG, WMA entre outros) e a oferta e popularização dos acessos à internet de alta velocidade tornaram possível a distribuição de música por meio da rede mundial, que foi impulsionada ainda pela criação das redes $\mathrm{P} 2 \mathrm{P}$. A troca de arquivos por meio da rede mundial dispensa a utilização dos suportes físicos, cuja comercialização foi a principal fonte de receitas da indústria nos últimos 50 anos. O que era antes dependente de canais de distribuição físicos e atividades logísticas ganhou uma alternativa virtual de baixo custo, pela troca de arquivos digitais pela internet.

O panorama atual é o de queda das vendas de suportes físicos, atribuída por muitos, entre eles os representantes da própria indústria, à pirataria, tanto física, devido à venda de cópias não autorizadas, quanto virtual, na internet, principalmente por meio das chamadas redes $\mathrm{P} 2 \mathrm{P}$ (peer to peer). A questão no enquanto é controversa: a indústria credita a queda de vendas à pirataria, enquanto outros atribuem a retração na demanda a outros fatores, como a mudança no perfil de consumo dos jovens, sendo a pirataria um sintoma, e não causa do problema (e.g. LEYSHON et al., 2005).

\section{A desverticalização da indústria fonográfica}

As empresas da indústria fonográfica nasceram verticalmente integradas. As fabricantes de reprodutores do início do século XX se tornaram as majors da década de 1950 (com exceção da Capitol, que foi criada como gravadora, as maiores empresas da época, como a EMI, a Columbia, a RCA-Victor e a Decca tiveram sua origem ligada a produtoras de fonógrafos). Elas possuíam elencos de artistas e instrumentistas, estúdios de gravação, fábricas de suportes, além de produzirem os reprodutores. Ao longo do tempo, as empresas foram progressivamente se desverticalizando, até limitarem-se à produção e divulgação de conteúdo. Como visto, o crescimento 
do mercado, o desenvolvimento tecnológico e a disseminação de competências influenciam o processo de desverticalização das empresas. No processo de desverticalização da indústria fonográfica, o desenvolvimento tecnológico é o fator de maior influência isolada.

$\mathrm{O}$ primeiro avanço significativo na tecnologia de produção de fonogramas ocorreu na década de 1950, com a introdução da gravação em fita magnética, que reduziu tanto investimentos como custos de produção. $\mathrm{O}$ resultado foi o surgimento das primeiras gravadoras independentes. Algumas dessas fortaleceram-se e estabeleceram selos (marcas) com forte identidade, como Atlantic, Motown e Electra, Savoy, Chess, Modern, Imperial e Specialty (ALEXANDER, 1994; PETERSON; BERGER, 1975).

Ao constatar o sucesso das novas empresas e dos novos gêneros, a resposta das majors foi, fazendo valer os seus recursos financeiros e o domínio sobre a cadeia, estabelecer controle ou influência sobre as gravadoras independentes, seja pela sua aquisição (mantendo parte de sua autonomia) ou pelo estabelecimento de acordos de distribuição. O modelo dominante passou a ser então o "sistema aberto" (LOPES, 1992), em que as majors mantinham controle sobre a produção de cópias, sua distribuição e divulgação, explorando economias de escala nessas atividades, ao mesmo tempo em que, além de produzir conteúdo internamente, externalizaram a criação de conteúdo para fornecedores cativos, as gravadoras independentes que controlavam. Com isso, conseguiram diversificar os gêneros musicais que ofereciam e atingir novos segmentos do mercado. As independentes com quem se relacionavam, serviam, dessa forma, como laboratório para prospecção de novas tendências e artistas.

O panorama permaneceu inalterado até o final da década de 1980: grandes empresas dominando o mercado, com estratégias centradas no lançamento de grandes sucessos (a chamada estratégia superstar ou blockbuster), e atendendo a nichos por meio de selos específicos. Somente o advento da tecnologia digital modificou o panorama, quando, a partir dos anos 1980, houve novo surgimento de gravadoras independentes (HESMONDHALGH, 1998). Novamente a diminuição dos investimentos necessários e a redução de custos foi o fator determinante para o surgimento das novas empresas.

Porém, mesmo o advento da tecnologia digital não modificou drasticamente a forma de distribuição e comercialização de fonogramas, que continuaram dependentes de um suporte físico. Foi somente com o desenvolvimento da internet, e das tecnologias complementares de compactação de arquivos e do acesso de banda larga, que a distribuição virtual se tornou possível. Uma das primeiras reações das empresas foram as ações legais contra a distribuição virtual pelas redes P2P, sob o argumento de ilegalidade pelo não respeito aos direitos de autor. O início dos anos 2000 encontra as majors envolvidas em três ações: a externalização das atividades de manufatura de suportes, as ações legais contra as redes P2P e as tentativas de estabelecer modelos próprios de distribuição virtual.

Enquanto as tentativas das majors em estabelecer lojas virtuais próprias resultaram em fracassos, as ações legais tiveram sucesso parcial: foram bem sucedidas nos tribunais, porém não foram efetivas em impedir o avanço das redes P2P. Assim, a ação mais importante realizada pelas majors foi a venda de ativos produtivos para empresas especializadas, que, seguindo o modelo adotado pelos grandes fornecedores por contrato da indústria eletrônica, passaram a oferecer serviços de fabricação de suportes físicos e de logística para a indústria fonográfica. Essas empresas fornecem não somente para a indústria fonográfica, mas também para a indústria cinematográfica e para a de jogos eletrônicos, valendo-se da semelhança entre produtos, utilizando assim sua capacidade de produção e aproveitando com isso de economias de escala. O Quadro 1 destaca os principais fornecedores especializados mundiais.

Se a distribuição digital não foi aproveitada pelas grandes empresas, o mesmo não se pode afirmar das pequenas empresas. Muitos empreendedores se valeram da queda nos custos de produção e das possibilidades de divulgação e distribuição e fundaram pequenas gravadoras. Alem disso, novos modelos de negócio surgiram entre as novas empresas (PAPAGIANNIDIS; BERRY; PETCHEY, 2005), que começaram a explorar novas possibilidades de geração de receitas.

O surgimento de empresas especializadas, não limitado somente aos grandes fornecedores, mas incluindo pequenas gravadoras e estúdios, conferiu à cadeia de produção musical uma morfologia de rede, na qual participam grandes empresas e diversos pequenos e médios fornecedores (GRAHAM et al. 2004; LEYSHON et al., 2005). Leyshon et al. (2005) argumentam inclusive que existem diferentes redes em cada processo da cadeia, com as gravadoras ocupando alguns dos nós centrais. Já Alkmim et al. (2005) enfatizam não somente que a cadeia de produção musical teria morfologia de rede, mas que ela teria um caráter repetitivo em diferentes escalas, o que lhe conferiria a característica de um fractal.

Confrontando o processo de desverticalização da cadeia de produção musical com os fatores relacionados na seção anterior, Quadro 2.

\section{O panorama da indústria fonográfica independente nacional}

O desenvolvimento da indústria nacional segue, em grande medida, o da indústria internacional. Relatos cuidadosos e detalhados da evolução histórica 
da indústria, desde a década de 1960, podem ser encontrados em Vicente (2006), Dias (2008) e Morelli (2009), e, por este motivo, o presente texto focaliza somente as modificações recentes do setor e, em particular, o segmento independente, pois elas são representativas do processo de desconcentração e desverticalização da indústria nacional. O mercado nacional, assim como boa parte do mundo, é dividido entre as majors, EMI, Sony, Universal e Warner, e diversas empresas nacionais. Entre elas figuram empresas ligadas a grupos de comunicação nacionais, como a Som Livre, e gravadoras de música gospel, que fazem parte da Associação Brasileira dos Produtores de Discos (ABPD), juntamente com as majors. Além delas, existem cerca de 300 gravadoras independentes em atividade, entre as quais, aproximadamente 100 fazem parte da Associação Brasileira da Música Independente (ABMI). A produção independente, no Brasil e no mundo, é geralmente associada à inovação e qualidade.

Durante o ano de 2008, foram conduzidas algumas atividades para caracterizar o panorama da indústria independente nacional (definida como o conjunto de gravadoras não associadas à ABPD). Por meio do rol de associados da ABMI, de informações da literatura, especialmente de Vicente (2006), e de informações de distribuidores, concluiu-se, em primeiro lugar, que o número aproximado de gravadoras independentes em atividade no país é de 300. Por meio de informações dos sítios das empresas, quando disponíveis, e de contatos por correio eletrônico e por telefone, foi possível determinar o ano de fundação de 140 dessas empresas. A Figura 2 mostra o número acumulado de gravadoras ao longo do tempo, e o seu exame sugere, em primeiro lugar, que a produção independente começar a ganhar impulso a partir da década de 1980, o que corrobora tanto informações da literatura internacional, já comentada, como da nacional, que aponta o ano de 1977 como o marco inicial da produção independente brasileira (VICENTE, 2006). É possível também identificar duas acelerações no surgimento das gravadoras independentes, entre 1988 e 1997, e a partir daquele ano até o presente.

Quadro 1. Principais produtores mundiais de mídias físicas e serviços relacionados.

\begin{tabular}{|c|c|c|c|}
\hline Empresa & Capital & Fundação & Produtos e serviços oferecidos \\
\hline Memory Tech & Japão & 1985 & $\begin{array}{c}\text { Fabricação de suportes (DVD,CD, etc.), } \\
\text { logística de distribuição e estúdios de gravação }\end{array}$ \\
\hline Cinram & Canadá & 1969 & $\begin{array}{c}\text { Fabricação de suportes (DVD,CD, etc.) e } \\
\text { logística de distribuiçãa }\end{array}$ \\
\hline $\begin{array}{l}\text { EDC } \\
\text { (anteriormente Glenayre) }\end{array}$ & EUA & $\begin{array}{l}\text { Glenayre em } 1992 \\
\text { EDC em } 2007\end{array}$ & $\begin{array}{c}\text { Fabricação de suportes (DVD,CD, etc.) e } \\
\text { logística de distribuiçãa }\end{array}$ \\
\hline $\begin{array}{l}\text { Arvato } \\
\text { (anteriormente Sonopress) }\end{array}$ & Alemanha & 1958 & $\begin{array}{l}\text { Fabricação de suportes (DVD,CD, etc.), } \\
\text { logística de distribuição e e-commerce }\end{array}$ \\
\hline Novodisc & Espanha & $\begin{array}{c}\text { Início da } \\
\text { década de } 1990\end{array}$ & $\begin{array}{c}\text { Fabricação de suportes (DVD,CD, etc.) e } \\
\text { logística de distribuiçãa }\end{array}$ \\
\hline Sony DADC & Japão & nd. & $\begin{array}{c}\text { Fabricação de suportes (DVD,CD, etc.) e } \\
\text { logística de distribuição }\end{array}$ \\
\hline
\end{tabular}

Fonte: o autor.

Quadro 2. Principais eventos de desverticalização e fatores associados.

\begin{tabular}{|lll|}
\hline & \multicolumn{1}{|c|}{ Evento } & \multicolumn{1}{c|}{ Fator } \\
\hline Década de 1950 & Surgimento das primeiras gravadoras independentes & $\begin{array}{l}\text { Desenvolvimento tecnológico - redução } \\
\text { de investimentos e custos de produção } \\
\text { Crescimento do mercado }\end{array}$ \\
Década de 1980 & Novo surgimento de independentes & $\begin{array}{l}\text { Desenvolvimento tecnológico - redução } \\
\text { de escalas eficientes }\end{array}$ \\
Década de 2000 & Externalização da manufatura & $\begin{array}{l}\text { Desenvolvimento tecnológico - } \\
\text { Disseminação de competências e } \\
\text { modularização }\end{array}$ \\
& & $\begin{array}{l}\text { Desenvolvimento tecnológico - redução } \\
\text { de custos e de escalas eficientes }\end{array}$ \\
\hline
\end{tabular}

Fonte: o autor. 
Com o objetivo de ter um quadro mais claro do setor, além do levantamento do ano de fundação das empresas e de coleta de informações secundárias, foram também realizadas 10 entrevistas com gravadoras sediadas em São Paulo e no Rio de Janeiro, cujos dirigentes eram membros da diretoria da ABMI. As entrevistas foram presenciais, semiestruturadas, com duração de 1 a 2 horas, foram integralmente gravadas e transcritas. O Quadro 3 relaciona as empresas entrevistadas.

A maioria das gravadoras entrevistadas tem outras atividades geradoras de receitas, isto é, a atividade de produção fonográfica é uma derivação de outra atividade relacionada ou é somente uma no portfólio da empresa. Das dez empresas, duas empresas são destacadas a seguir pelo tipo de atividade que executam. Uma delas é uma gravadora cuja proposta é a de ser uma prestadora de serviços aos artistas. Ela se posiciona tanto no papel tradicional de gravadora, auxiliando o artista a desenvolver seu produto, produzindo os fonogramas e cuidando de

Quadro 3. Entrevistas realizadas.

\begin{tabular}{|lc|}
\hline \multicolumn{1}{|c}{ Atividade } & Localização \\
\hline Gravadora e produtora publicitária & $\mathrm{SP}$ \\
Gravadora & $\mathrm{SP}$ \\
Gravadora & $\mathrm{SP}$ \\
Gravadora e produtora publicitária & $\mathrm{SP}$ \\
Gravadora musical e de vídeo & $\mathrm{SP}$ \\
Distribuidora virtual & $\mathrm{RJ}$ \\
Gravadora e produtora cinematográfica & $\mathrm{RJ}$ \\
Gravadora e produtora de eventos & $\mathrm{RJ}$ \\
Gravadora, estúdio e revenda de & $\mathrm{RJ}$ \\
equipamentos & \\
Gravadora e estúdio & $\mathrm{RJ}$ \\
\hline
\end{tabular}

Fonte: O autor.

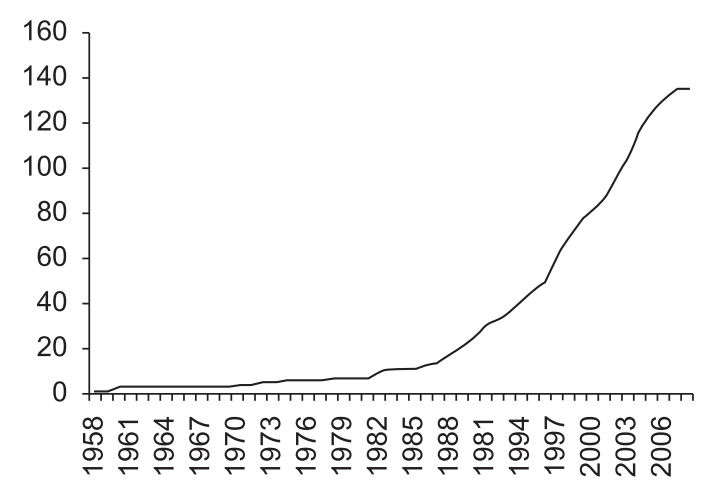

Figura 2. Número de gravadoras independentes brasileiras. Fonte: o autor. sua reprodução e distribuição, como também se coloca como prestadora de serviços, oferecendo seus serviços de produção e distribuição aos artistas. A diferença fundamental no segundo caso é que o artista contrata os serviços da gravadora, sendo seu o ônus do levantamento de capital e os riscos do lançamento da obra, ficando, porém, com os resultados e mantendo a autonomia sobre seu trabalho.

O segundo exemplo é o de uma empresa prestadora de serviços, que oferece uma gama de possibilidades de distribuição virtual de música, inclusive explorando o mercado da telefonia móvel, aquele que vem apresentando expressivos índices de crescimento na distribuição de música. Essa empresa é representativa da fusão de duas cadeias, a de produção musical e a de telecomunicações: para a primeira, a segunda representa uma alternativa de distribuição, enquanto que para esta, a primeira é a oportunidade da oferta de novos produtos.

\subsection{Empresa A - uma fornecedora especializada de serviços}

A Empresa A é uma gravadora fundada no início dos anos 2000 que se autodenomina "agência de produção cultural", indicando com isso que procura praticar um modelo de negócios diferenciado. De fato, segundo seus dirigentes, as receitas provenientes da venda de CDs têm pequena contribuição no faturamento da empresa. Enquanto para as gravadoras tradicionais a produção e venda de suportes físicos representa a maior parcela do faturamento, exigindo investimentos para o lançamento de novos títulos e uma administração voltada para a manutenção de um volume de vendas constante, capaz de pagar os investimentos realizados, no caso da Empresa A, uma das principais atividades é a prestação de serviços de produção, distribuição e divulgação de álbuns para os músicos. Seu principal cliente e gerador de receitas é o próprio artista e não o consumidor final. Porém ela não é apenas uma prestadora de serviços que permanece invisível para o mercado final. Aos olhos do consumidor, a Empresa A é uma gravadora como diversas outras. Sua estratégia de negócios diferenciada permanece transparente, pois, para o consumidor, é a Empresa A que oferece o álbum de um artista, assim como o fazem as outras gravadoras.

Porém, por trás do produto final, no lugar de uma empresa que contrata um artista, aplica seus recursos financeiros no desenvolvimento de um produto, remunera os artistas e retira seus lucros com as vendas realizadas, existe um artista que aplica seus próprios recursos, artísticos e financeiros, para a produção de seu álbum, e que para tanto contrata a Empresa A como uma prestadora de serviços especializada para cuidar de todo o processo. Essa, por sua vez, utiliza a sua experiência e conhecimento da cadeia produtiva, 
que em geral o artista não dispõe, para produzir um produto de menor custo e maior qualidade técnica que aquele que o artista conseguiria sozinho. Depois abre ao artista o acesso a pontos de venda selecionados, distribui seu álbum e se encarrega de promovê-lo.

A estratégia da Empresa A é possível porque, desde a queda nos custos de produção, criou-se no mercado o comportamento do artista que, seja por desejo de independência ou por falta de oportunidades, decide produzir seu próprio álbum. Esse tipo de ação teve o seu primeiro exemplo ainda no final da década de 1970, com o LP "Feito em casa", de Antônio Adolfo (VICENTE, 2006), cujo título sugestivo indicava que a produção do álbum havia sido integralmente planejada e executada pelo próprio artista. Se isso foi possível na década de 1970, a queda de custos com a tecnologia digital e o surgimento de diversos fornecedores especializados fez com que a possibilidade de uma produção "caseira" ficasse ainda maior a partir dos anos 1990.

Porém, apesar da facilidade de acesso aos meios de produção, existem duas dificuldades para a ação individual do artista: em primeiro lugar, muitos artistas desconhecem os detalhes das atividades do processo de produção e não possuem os contatos comerciais para coordenar a elaboração do seu álbum, o que faz com que muitas iniciativas de produção individual terminem em um produto caro e de qualidade insatisfatória. Soma-se a isso, conforme informação de dirigente da Empresa A, o próprio desinteresse de muitos artistas em supervisionar a produção técnica de seu álbum, pois consideram uma atividade difícil, preferindo dedicar-se somente à música. Dessa forma, muitos deles, de bom grado, contratam uma empresa que se encarregue da produção do álbum, exatamente o nicho de mercado explorado pela Empresa A.

De forma simplificada, o fluxo financeiro na cadeia de suprimentos, da mesma foram que o fluxo de informações, flui em sentido contrário ao fluxo material. Dessa forma, no modelo tradicional do setor, as gravadoras contratam artistas, produzem e comercializam suportes físicos com os registros das músicas (i.e., CDs), recebem as receitas provenientes das vendas aos consumidores por meio de seus canais de distribuição e pagam artistas e demais fornecedores. A Empresa A é um pequeno exemplo de subversão desse fluxo: ao se posicionar como prestadora de serviços para os artistas, ela produz e comercializa fonogramas que muitas vezes não são seus, recebendo pagamento dos artistas e repassando a eles as receitas das vendas ao consumidor. Dessa forma, embora o fluxo material continue o mesmo, o fluxo financeiro ganha alguma complexidade: por exemplo, em uma das modalidades praticadas pela Empresa A, o artista contrata a empresa, que se encarrega da produção e comercialização, utilizando a sua marca, e depois recebe e repassa as receitas de vendas ao artista. Em outra modalidade de negócios, a Empresa A investe parte do capital necessário para a produção do álbum, e depois divide as receitas proporcionalmente com o artista. Seu modelo de negócios tem a vantagem de diminuir significativamente o risco da empresa, pois o capital investido é do artista (parcial ou integralmente) ao mesmo tempo em que oferece um serviço diferenciado, produzindo um produto final que o artista não conseguiria sozinho, sem os seus serviços.

É evidente que para que esse modelo de negócios seja bem sucedido, a Empresa A precisa ser reconhecida pelos seus clientes, os artistas, como um fornecedor competente. Deve-se destacar nesse sentido o esforço realizado pela Empresa A no seu posicionamento mercadológico, pela manutenção de um catálogo diferenciado e bem focalizado (a empresa não assina contratos com artistas que julgue não adequados à sua linha estética), e de uma série de iniciativas promocionais, que visam sempre fortalecer o selo (marca) da empresa. A ação mercadológica da Empresa A, embora voltada para o consumidor final, serve para fortalecer a sua posição junto aos artistas, que veem o bom posicionamento da empresa no mercado como o um ponto forte da empresa e procuram seus serviços.

\subsection{Empresa B - os novos canais de distribuição virtuais e a convergência com a indústria de Telecom}

A Empresa B também é de fundação recente, e faz parte de um conglomerado de empresas que se dedica a negócios relacionados à internet e é uma distribuidora de conteúdo audiovisual digital. Os negócios da Empresa B podem ser divididos em duas categorias: aqueles relacionados ao comércio virtual (pela internet); e os relacionados à oferta de conteúdo para empresas de telecomunicações. Na primeira categoria encontram-se a loja virtual da empresa, onde o consumidor final pode comprar fonogramas (músicas individuais) ou álbuns. A Empresa B também é um fornecedor de serviços digitais (Digital Service Provider-DSP), isto é, ela presta serviços a outras empresas da internet, por exemplo, os portais dos grandes provedores de acesso (ISP - Internet Service Providers), que contratam a Empresa B para elaborar e administrar suas lojas virtuais de música. Nesse caso, quando o consumidor navega pelas páginas de venda de música de um portal que seja cliente da Empresa B, ele na verdade acessa os próprios serviços da Empresa B, que faz a comercialização de música para aquele portal-cliente. Assim, a Empresa B atua tanto como varejista de música digital, quanto como um fornecedor de serviços digitais.

Na segunda categoria de serviços, a Empresa B atua como agregadora de conteúdo para empresas 
de telecomunicações. Acompanhando a tendência do setor, as operadoras de telefonia celular têm ampliado seu leque de serviços e, além dos serviços de comunicação, têm oferecido conteúdo a seus assinantes. A Empresa B, utilizando seu conhecimento da cadeia de produção musical e seu contato com as gravadoras, licencia fonogramas e organiza o conteúdo artístico para que as operadoras de telefonia os ofereçam a seus assinantes, sem que para isso tenham a necessidade de administrar o contato com artistas, editoras e gravadoras, o licenciamento de conteúdo e o pagamento de direitos autorais, atividades realizadas pela Empresa B.

Além desse serviço, a Empresa B também atua como empresa integradora. Nesse modelo, ela oferece, além do conteúdo, como já citado, também a solução tecnológica relativa ao sistema de controle e cobrança de consumo pelo assinante, atividade que é realizada pela própria operadora no primeiro caso. Nesse caso, a Empresa B oferece a chamada solução completa para seu cliente, que engloba tanto o conteúdo como a solução tecnológica para a operação do serviço. A venda de fonogramas por meio de telefones celulares é uma das modalidades de venda de música digital que mais cresce no mundo. O relatório da IFPI (International Federation of the Phonografic Industry) de 2007 aponta crescimento nas vendas por telefone nos EUA, onde somente uma operadora registrou mais de 10 milhões de faixas de música vendidas desde o final de 2005. Na Europa, segundo o mesmo relatório, também há crescimento, porém um pouco mais modesto. No Brasil, de acordo com informações veiculadas pela imprensa, $76 \%$ das receitas da venda de música digital são oriundas da telefonia celular.

A atuação da Empresa B representa a convergência entre as cadeias de produção musical e a de telecomunicações. Ela representa duas tendências: a da cadeia de música cuja distribuição em formato digital por telefones móveis vem crescendo, como apontam dados nacionais e internacionais, e a da cadeia de telecomunicações, em que as operadoras passam a oferecer conteúdo além de serviços de comunicação a seus assinantes. A Empresa B se insere como um fornecedor especializado de conteúdo para as operadoras. Para atuar nessa interface, a Empresa B precisa conhecer ao mesmo tempo as duas cadeias, atuando como um gatekeeper, isto é, uma organização capaz de comunicar-se ao mesmo tempo com empresas de ambos os lados. Isso exige conhecimento tanto do mercado de música e de seus fornecedores (as gravadoras, editoras e artistas) quanto o desenvolvimento de competências técnicas para dialogar com as operadoras de telecomunicações. A Empresa B parece estar sendo bem sucedida em sua estratégia, pois, conforme informações de seus dirigentes, conseguiu fechar contratos de fornecimento de conteúdo, nas duas modalidades, com grandes operadoras de telefonia.

É interessante notar que a venda de fonogramas por telefone, embora do ponto de vista tecnológico seja similar à distribuição de música digital pela internet, apresenta uma diferença fundamental em relação a essa: permite o uso do mesmo mecanismo de apropriação de receitas, praticado pelas gravadoras com os suportes físicos, apenas em escala reduzida: a cobrança praticada pela indústria (LEYSHON et al., 2005) tinha como unidade o álbum, i.e., um conjunto em geral de 10 a 14 músicas, ou fonogramas. Na venda por telefone, a unidade de comercialização passa a ser o fonograma individual, porém a estrutura de remuneração permanece a mesma, com as divisões da receita obedecendo aos padrões conhecidos pelos atores da indústria. A mudança acontece apenas na escala: uma mesma receita corresponde a um volume muito maior de transações; e uma unidade de conteúdo corresponde a uma receita muito menor.

Em contraposição, a distribuição pela internet ainda não conseguiu firmar processos de apropriação da renda efetivos e aceitos por todos os envolvidos, seja porque simplesmente o consumidor encontra alternativas de acesso gratuito à música (legal ou ilegal) e não efetua qualquer pagamento ou porque, entre os modelos de distribuição desenvolvidos atualmente, em alguns, há dificuldades de estabelecer o mecanismo de apropriação, como, por exemplo, na venda de assinaturas para download ou streaming. Por exemplo, no sistema de assinatura para download, uma das formas de pagamento utilizadas pelo serviço é a do preço fixo por período, sem limite de acesso. Neste caso, não é possível vincular o pagamento de direitos a cada música consumida, e o provedor precisa realizar os pagamentos utilizando valores médios e rateios. Por esse motivo, é de se esperar que as empresas que atuam e dominam o mercado (as majors) tenham mais facilidade na operação e da venda de fonogramas por telefone, aceitando-a sem problemas, pois a forma de operação é conhecida e familiar.

\section{Discussão}

Embora o padrão externalização de atividades ocorrido na indústria fonográfica seja, em certo sentido, similar ao ocorrido na indústria eletrônica, com o estabelecimento de fornecedores especializados que prestam serviços de manufatura e logística, existe uma diferença fundamental: não há barreiras de entrada econômicas para a atividade de produção do conteúdo musical. Com isso, a presença de fornecedores especializados deu condições para o crescimento da atividade independente, e os exemplos descritos ilustram duas possibilidades de atuação dentro do panorama atual. O primeiro deles mostra que um dos papéis que as gravadoras podem desempenhar 
na cadeia, especialmente as de pequeno porte, é a de provedores de capacidade de coordenação. Os serviços necessários para a produção e comercialização de fonogramas estão disponíveis no mercado, porém muitos produtores de conteúdo, os artistas, não têm informação e capacidade de coordenação para utilizá-los. Portanto, existe mercado para esse tipo de serviço. No caso da Empresa A, altera-se inclusive a relação gravadora-artista. Se antes, em muitos casos, essa era uma relação assimétrica, com boa parte do poder permanecendo do lado da gravadora, no caso estudado, a relação passa a se aproximar de uma parceria. A oferta de serviços de coordenação tem a vantagem adicional de deixar o risco do empreendimento para o próprio artista, exigindo menos recursos financeiros da Empresa A, e parece ser uma alternativa capaz de acomodar os diversos interesses envolvidos, bem como capaz de oferecer ao mercado uma maior diversidade de produtos culturais.

Já o segundo caso ilustra um fenômeno contemporâneo: a convergência entre as cadeias fonográfica e de telecomunicações. Se antes as relações entre essas cadeias eram pequenas, com a internet e o avanço da telefonia móvel, elas passam a ter forte vinculação. A expansão dos serviços de telecomunicações em direção à oferta de conteúdo é caminho natural para a distribuição virtual de música. A simbiose entre as duas cadeias é um fato, e as empresas que tiverem as competências necessárias para atuar na interface entre elas terão um nicho de mercado promissor, como mostra o segundo exemplo deste texto. Deter o conhecimento das particularidades da cadeia de produção musical, dos seus principais atores e dos seus mecanismos de apropriação e, ao mesmo tempo, dos aspectos técnicos da cadeia de telecomunicações é a competência necessária para as empresas que pretendem se estabelecer neste nicho de serviços.

\section{Conclusões}

A evolução da cadeia produtiva da música reflete o crescimento e a diversificação do mercado de entretenimento, ao mesmo tempo em que ilustra os impactos da evolução tecnológica na produção artística. O desenvolvimento tecnológico criou a indústria fonográfica e influenciou profundamente a sua estrutura e configuração. Da invenção do suporte físico, que possibilitou a comercialização de fonogramas, sua evolução pelos diferentes formatos, até a tecnologia digital, cada fase do desenvolvimento tecnológico acarretou modificações na atuação e estrutura do setor.

Do ponto de vista técnico, a evolução das tecnologias utilizadas na produção e a disseminação de competências no setor criaram fornecedores especializados em todas as atividades da cadeia, levando à desverticalização das grandes empresas, e abrindo a possibilidade para pequenas empresas produzirem e comercializarem conteúdo, sem instalações e grandes investimentos em equipamentos. $\mathrm{O}$ avanço da tecnologia de informação e comunicação teve ainda outro efeito: ele quebrou a ligação entre conteúdo e suporte no produto fonográfico. Dessa forma, para a indústria fonográfica, ao contrário da experiência de outras indústrias, a produção pode ser não somente coordenada à distância, mas o próprio conteúdo pode ser transmitido entre as etapas do processo produtivo sem que seja necessário fluxo físico chegando até o consumidor final. Somente no caso da comercialização por meio de suportes físicos, que deve sobreviver em um nicho de mercado, assim como o disco de vinil resiste até hoje, é que o fluxo físico se estabelece na etapa final da distribuição.

Além disso, a queda constante dos preços de computadores pessoais e o desenvolvimento dos softwares associados tiveram outro efeito, agora na própria produção de conteúdo. $\mathrm{O}$ acesso facilitado às tecnologias de produção permitiu o crescimento da cena independente, o surgimento da figura do artista-empreendedor, e mais ainda, permitiu que parte da produção musical fluísse de forma espontânea e descentralizada em nichos de mercado, criando públicos e artistas à margem do mainstream, como por exemplo, o tecnobrega no Pará.

A cadeia de produção musical está longe de ter atingido uma configuração estável. Os exemplos deste artigo mostram como novos papéis estão surgindo e a relação de forças pode se alterar na cadeia. Embora as empresas produtoras de conteúdo tenham lugar garantido no futuro, o modelo de apropriação ainda está indefinido e, enquanto as grandes empresas lutam para manter suas posições, os pequenos produtores crescem com vigor. O impacto das recentes evoluções tecnológicas ainda está longe de ter terminado, e há necessidade de mais estudos sobre o assunto.

\section{Agradecimentos}

$\mathrm{O}$ autor agradece o apoio financeiro da FAPESP, na forma do auxílio 07/02366-1, os alunos de iniciação científica Renan Kabariti, Gonzalo Peinado, Cínthia Toma e Thiago Lobão pelo auxílio com os dados, e assim como os revisores do artigo.

\section{Referências}

ALEXANDER, P. J. New technology and market structure: evidence from the music recording industry. Journal of Cultural Economics, v. 18, p. 113-123, 1994.

ALKMIM, A. C. et al. Cadeia produtiva da economia da música. Rio de Janeiro: PUCRJ, 2005.

ANAND, N.; PETERSON, R. A. When market information constitutes fields: sensemaking of markets in the commercial music industry. Organization Science, v. 11 , n. 3 , p. $270,2000$. 
ASSOCIAÇÃO BRASILEIRA DOS PRODUTORES DE DISCOS - ABPD. Mercado Brasileiro de Música 2006. Rio de Janeiro: ABPD, 2006.

BRUSONI, S.; PRENCIPE, A. Unpacking the black box of modularity: technologies, products and organizations. Industrial and Corporate Change, v. 10, n. 1, 2001.

CAVES, R. E. Creative industries. Cambridge: Harvard University Press, 2000.

DIAS, M. T. Os donos da Voz. São Paulo: Boitempo, 2008.

GEREFFI, G.; HUMPHREY, J.; STURGEON, T. The governance of global value chains. Review of International Political Economy, v. 12, n. 1, p. 78-104, 2005.

GRAHAM, G. et al. The transformation of the music industry supply chain. International Journal of Operations and Production Management, v. 24, n. 11, p. 1087-1103, 2004.

HANSMAN, H.; MULDER, C. H.; VERHOEFF, R. The adoption of the compact disk player: an event history analysis for the Netherlands. Journal of Cultural Economics, v. 23, p. 223-235, 1999.

HESMONDHALGH, D. The british dance music industry: a case study of independent cultural production. British Journal of Sociology, v. 49, n. 2, 1998.

INTERNATIONAL FEDERATION OF THE PHONOGRAPHIC INDUSTRY - IFPI. Digital music report 2006. London: IFPI, 2006. Disponível em: <http:// www.ifpi.org>. Acesso em: 10 dez. 2007.

INTERNATIONAL FEDERATION OF THE PHONOGRAPHIC INDUSTRY DIGITAL - IFPI. Formats continue to drive the global music market. 2006. Press Release. Disponível em: <http://www.ifpi. org>. Acesso em: 10 dez. 2007.

LANGLOIS, R. N. The vanishing hand: the changing dynamics of industrial capitalism. Industrial and Corporate Change, v. 21, n. 2, p. 351-385, 2001.

LEYSHON, A. et al. On the reproduction of the musical economy after the internet. Media, Culture and Society, v. 27, n. 2, p. 177-209, 2005.

LOPES, P. D. Innovation and diversity in the popular music industry, 1969 to 1990. American Sociological Review, v. 57, 1992.

MALERBA, F. et al. Vertical integration and disintegration of computer firms: a history-friendly model of the coevolution of the computer and semiconductor industries. Industrial and Corporate Change, v. 17, n. 2, p. 197-231, 2008.

McCOURT, T.; BURKART, P. When creators and consumers collide: Napster and the development of on-line music distribution. Media, Culture and Society, v. 25, p. 333-350, 2003.

MORELLI, R. C. L. Indústria fonográfica: um estudo antropológico. 2. ed. Campinas: Ed. UNICAMP, 2009.

PAPAGIANNIDIS, S.; BERRY, J.; PETCHEY, T. The long and winding road? E-business models for small independent record labels. WSEAS Transactions in Information Science \& Applications, v. 2, n.10, p. 1723-1730, 2005.

PETERSON, R. A. Why 1955? Explaining the Advent of Rock Music, Popular Music, v. 9, n. 1, Jan., 1990, p. $97-116$

PETERSON, R. A.; BERGER, D. Cycles in symbolic production: the case of popular music. American Sociological Review, v. 40, 1975.

STROLB, E. A.; TUCKER, C. The dynamics of chart success in the u.k. Pre-recorded popular music industry. Journal of Cultural Economics, v. 24, p. 113-134, 2000.

STURGEON, T. J. Modular production networks: a new american model of industrial organization. Industrial and Corporate Change, v. 11, n. 3, p. 451-496, 2002.

TIGRE, P. B. Gestão da inovação. Rio de Janeiro: Campus, 2006.

TOWNLEY, B.; BEECH, N.; McKINLAY, A. Managing in the creative industries: managing the motley crew. Human relations, v. 62, p. 939 - 962.

ULRICH, K. The role of product architecture in the manufacturing firm. Research policy, v. 24, p. 419-441, 1995.

UNESCO. $25 F A Q$. Disponível em: <http://www.unesco. org >. Acesso em: 23 maio 2006.

VICENTE, A. A vez dos independentes(?):um olhar sobre a produção musical independente do país, e-compós. Revista da Associação Nacional de Pós-Graduação em Comunicações, 2006.

VINET, M. Entertaiment industry. Quebec: Wandem Publishing, 2005.

VOGEL, H. L. Entertaiment industry economics. Cambridge, UK: Cambridge University Press, 2004. 